\title{
Terceira idade e doenças crônicas: Contrastes e paradoxos
}

\section{Theddalyanddroricdseses Contrastsandparadbxes}

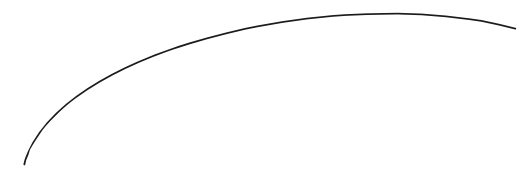

Apesar dos avanços nas políticas públicas de inclusão e compensação social para a pessoa idosa, ainda se observa grande iniquidade social no Brasil. Além disso, a prevalência das doenças crônicas não-transmissíveis continua a aumentar, pois a população continua envelhecendo aceleradamente e não se generalizaram programas eficientes de promoção da saúde e de prevenção primária. A consequência é o aumento da morbidade por doenças crônicas preveníveis, associadas à incapacidade. Por outro lado, as doenças crônicas geram ônus sobre a Seguridade Social, e em consequência, sobre a sociedade. A população idosa é um grupo populacional heterogêneo que experimentou trajetórias de vida diferenciadas que afetarão seu bem-estar na fase final de suas vidas. Essas trajetórias são fortemente afetadas pelas desigualdades sociais, regionais, de gênero e raciais.

Esses contrastes e paradoxos são apresentados neste número da RBGG, em 13 artigos originais, um artigo de revisão, um artigo de atualização e um relato de caso, confirmando-se diferenças importantes de comportamentos diante de fatores de risco, do acesso e da utilização de serviços de saúde.

O primeiro artigo original trata do olhar e o sentir do idoso no pós-queda. $\mathrm{O}$ autor principal é da Universidade Católica de Goiás (PUC-Goiás). O segundo apresenta uma comparação entre os métodos de estimativa pela área adiposa do braço, pela dobra cutânea tricipital e por bioimpedância tetrapolar e vem da Universidade Federal Rural do Rio de Janeiro. O terceiro explora a antropometria de idosos residentes no município de JoinvilleSC e é proveniente da Universidade da Região de Joinville, do Programa de Mestrado em Saúde e Meio Ambiente. O quarto texto demonstra a correlação entre equilíbrio e ambiente domiciliar como risco de quedas em idosos com acidente vascular encefálico e vem da Universidade Estadual do Sudoeste da Bahia, do Curso de Fisioterapia em Jequié. Em seguinda, o quinto artigo original trata dos fatores associados à polifarmácia em idosos institucionalizados e é proveniente do Setor de Geriatria do Departamento de Medicina da Irmandade da Santa Casa de Misericórdia de São Paulo. O texto seguinte apresenta as práticas de letramento no processo de envelhecimento e foi realizado na Universidade Tuiuti do Paraná, Faculdade de Ciências Biológicas e da Saúde de Curitiba. Já o sétimo compara a antropometria e o perfil glicêmico de idosos diabéticos praticantes de atividade física regular e não-praticantes na Universidade de Fortaleza, Departamento de Educação Física. O oitavo apresenta a prevalência e fatores associados a quedas em idosos em um município do Rio de Janeiro e é da Universidade Aberta da Terceira Idade da Universidade do Estado do Rio de Janeiro. O nono artigo original realiza uma avaliação sensório-motora do tornozelo e pé entre idosos diabéticos e não-diabéticos na Universidade Católica de Brasília, Faculdade de Fisioterapia. Segue-se o décimo artigo, que avalia a qualidade de vida em idosas residentes em ambientes urbano e rural e é uma produção 
da Universidade Castelo Branco, Programa de Pós-graduação Stricto Sensu em Ciências da Motricidade Humana, no Rio de Janeiro. O décimo primeiro artigo é um estudo da mortalidade em população idosa de municípios do Rio Grande do Sul no período de 1996 a 2004, realizado na Universidade Federal de Ciências da Saúde de Porto Alegre, Curso de Fisioterapia. Segue-se uma análise temporal das internações hospitalares e óbitos causados por doenças do aparelho respiratório em idosos, realizado em Minas Gerais, no Centro Universitário do Leste de Minas Gerais, Ipatinga-MG. E o último artigo original é "O fim da linha"? Etnografia da alimentação de idosos institucionalizados - reflexões a partir das contribuições metodológicas de malinowski”, da Faculdade de Ciências Médicas da Universidade do Estado do Rio de Janeiro.

Enriquecendo ainda este número da RBGG, temos um artigo de revisão, intitulado "Ginkgo biloba e memória: revisão sistemática”, proveniente da Unidade de Terapia Intensiva do Hospital Universitário Gaffrée e Guinle, no Rio de Janeiro. Na seção de atualização, temos o artigo "Exercício físico e o processo saúde-doença no envelhecimento", da Universidade de São Paulo, Escola de Educação Física e Esportes de Ribeirão Preto. E finalmente há um interessante relato de caso da equipe de cirurgia de urgência do Hospital e Maternidade São Cristóvão, em São Paulo: "Ileo biliar: uma complicação da doença calculosa da vesícula biliar".

Como novidade, neste número apresentamos o novo formato da revista, maior e facilitando bem mais seu manuseio.

Também temos a honra de anunciar a inclusão de mais quatro integrantes do corpo editorial da RBGG, os professores doutores Carina Berterö, Catalina Rodriguez Ponce, Maria da Graça de Melo e Silva, Ricardo Oliveira Guerra e X. Anton Alvarez.

Enfim, a RBGG continua evoluindo e empenhada em cumprir seu papel de vanguarda da área do envelhecimento no Brasil e, nesta oportunidade, convida você a participar deste esforço, enviando sua contribuição. 